\title{
Larngeal Manifestations of Relapsing Polychondritis
}

\author{
Abdul Latif Hamdan, Doja Sarieddine \\ Department of Otolaryngology, Head and Neck Surgery, American University of Beirut Medical Center, Beirut, Lebanon. \\ Email: ds28@aub.edu.lb
}

Received April 12 $2^{\text {th }}, 2013$; revised May 12 $2^{\text {th }}, 2013$; accepted May 19 , $^{\text {th }} 2013$

Copyright (C) 2013 Abdul Latif Hamdan, Doja Sarieddine. This is an open access article distributed under the Creative Commons Attribution License, which permits unrestricted use, distribution, and reproduction in any medium, provided the original work is properly cited.

\begin{abstract}
The incidence of Relapsing Polychondritis is estimated to be 3.5 cases per million with only 600 cases being reported in the world. It can affect any age ranging from 5 to 84 years with predominance in the fourth and fifth decade. Male to female ratio varies from 1:1 to 1:3. It is believed to be an immunologic reaction to collagen Type II which is predominantly presented in the cartilaginous structures of the body and in the eye. The diagnosis is based on the presence of three or more clinical signs, one clinical sign in addition to histological confirmation, or involvement of two or more sites with a favorable response to treatment based on Mc Adam diagnostic criteria. The otolaryngologic manifestations of RP span the ears, nose, larynx and tracheobronchial tree. The symptoms include change in voice quality, respiratory discomfort, stridor, dyspnea, cough, chocking, anterior neck tenderness mainly over the thyroid cartilage and cricoid cartilages, aspiration and difficulty in swallowing. The laryngeal manifestations should be evaluated using high resolution computerized tomography, Magnetic resonance imaging, pulmonary function testing, plain radiography and pulmonary function testing.
\end{abstract}

Keywords: Relapsing Polychondritis; Larynx; Stridor

\section{Introduction}

Relapsing polychondritis RP is an inflammatory disease of the cartilaginous structures. It was first described by Jaksch-Wartenhorst in 1923 as polychondropathia [1]. Since then, several names have been attributed to this disease among which are chondromalacia, relapsing polychondritis, diffuse chondylosis, chronic atrophic polychondritis and dyschondroplasia [2-7]. The term relapsing polychondritis, introduced by Pearson et al. in 1960, is most commonly used in the literature [4]. The course of the disease is episodic and progressive affecting various organs in the body rich in proteoglycan, such as the peripheral joints, eyes, heart, blood vessels and kidneys. The otolaryngologic manifestations of RP span the ears, nose, larynx and tracheobronchial tree. In this review, the authors will present a comprehensive analysis of the literature on the laryngeal manifestations of relapsing polychondritis.

\section{Method}

A search of the literature via MEDLINE (PubMed) using relapsing polychondritis and larynx as key words was performed by the authors. Relevant articles were reviewed and information retrieved was stratified based on epidemiology, pathogenesis and etiology, clinical course of the disease and its treatment.

\section{Epidemiology}

Relapsing polychondritis is rare. The incidence is estimated to be 3.5 cases per million with only 600 cases being reported in the world [8]. The true prevalence of this disease is blurred because RP is often misdiagnosed and its symptoms are ill defined. Patients are invariably seen by many specialists before the diagnosis is made. Once affected, the five year survival is reduced to $74 \%$ and the 10 years to $55 \%$. Relapsing polychondritis can affect any age ranging from 5 to 84 years with predominance in the fourth and fifth decade $[9,10]$. Male to female ratio varies from 1:1 to $1: 3$. Racial distribution is controversial despite the fact that the greatest number of cases has been reported in Caucasians [1,11]. Heredity plays no role in acquiring RP because no familial reports have been described. Pregnancy remains a controversial influence in cases of congenital relapsing polychondritis $[8,9,12,13]$. 


\section{Pathogenesis and Etiology}

There is growing evidence in the literature that relapsing polychondritis is an immunologic reaction to collagen Type II which is predominantly present in the cartilaginous structures of the body and in the eye. Almost one third of patients with RP exhibit circulating antibodies to type II collagen during the acute phase of the disease $[14,15]$. Several authors have demonstrated the presence of cellular immune reactions and auto antibodies to type II collagen, the titers of which were significantly higher than the titers against constituent alpha-1(II) chains. This has led to the conclusion that the high antibody titers to type II collagen are primary and not secondary to the inflammatory process with destruction of cartilage [14]. A recent report by Lang $B$ et al. has demonstrated an increase in HLA-DR4 antigen with no subtype predominance in patients with RP. Further corroboration to the reports by Dolen et al., Ebringer et al., Foidart et al. and many others on the autoimmune nature of this disease, Courtenay et al. has demonstrated that arthritis can be induced by immunization with native type II collagen in rats and mice [16].

\section{Diagnosis}

The main key to the diagnosis of RP is clinical. Several diagnostic criteria have been described by several authors, namely Damiani and Levine, Michet et al., and McAdam [17-19]. The diagnosis is based on the presence of three or more clinical signs, one clinical sign in addition to histological confirmation, or involvement of two or more sites with a favorable response to treatment [20].

There are no reliable markers to the diagnosis of relapsing polychondritis. The yield of laboratory tests, namely elevated white counts, erythrocyte sedimentation rate and anemia, is usually non specific. The presence of anticollagen type II antibodies usually correlates with the severity of the disease and is mostly pronounced in the acute phase, though several authors have indicated limited diagnostic value for the presence of these antibodies $[14,21]$. Other immunologic tests such as rheumatoid factor and antinuclear antibodies may be positive indicating the presence of concomitant autoimmune diseases. In a study by McAam LP et al., almost one third of patients with RP may have coexistent autoimmune rheumatologic diseases [22].

The laryngeal manifestations of relapsing polychondritis should be evaluated thoroughly in view of the life threatening sequel of this disease, namely airway obstruction, collapse, and possibly death. The investigation should include high resolution computerized tomography, pulmonary function testing, plain radiography and pulmonary function testing. On imaging, calcific deposits in the tracheal cartilage may be seen in chronic cases of RP.
Based on reports by Port et al. and Oddone et al. computerized tomography is very helpful in limiting the differential diagnosis in patients with narrowing of the airway $[23,24]$. High resolution computerized tomography may yield signs of tracheal collapse, cartilage destruction, thickening, and fibrosis and airway stenosis. One of the main limitations of this diagnostic test is the difficulty in differentiating edema from fibrosis. Magnetic resonance imaging on the other hand correlates well with the histopathologic findings of this disease. It is a better modality than computerized tomography in differentiating inflammation from fibrosis [24-26]. Whereas inflammation is hyperintense on T2 - weighted images with no enhancement on T1 weighted images after the administration of gadolinium, chronic fibrosis is hyperintense on $\mathrm{T} 1$ and T2 weighted images and shows minimal enhancement after contrast injection.

Dynamic airway disease and airway collapse are better assessed using dynamic expiratory computerized tomography imaging and or cinebronchographic studies. Neeson et al. has also reported on the usage of $\mathrm{M}$ fluoroscopy with gradient echo technique for dynamic real time imaging of the larynx capturing up to 64 images in less than a minute [25]. Though bronchoscopy is very useful, it is advisable to avoid airway instrumentation because of serious side effects $[27,28]$.

Flow-volume loop analysis may reveal fixed or dynamic intra- or extra-thoracic airway obstruction.

\section{Laryngeal Manifestation}

In addition to the systemic symptoms of RP, namely fever, malaise and polyarthropathy, patients may suffer from otolaryngologic manifestations. These include auricular and nasal chondritis, in addition to laryngotracheal disease. Symptoms of auricular chondritis such as swelling and redness of the ears are the most common presenting symptoms. Other less common manifestations of RP are vestibular dyspfunction and hearing loss. In view of its potential fatal outcome, involvement of the laryngotracheal complex is the most alarming. Between 10\% - 50\% of death related to RP can be secondary to laryngotracheal involvement [29]. Close to fifty percent of patients with RP have laryngotracheal manifestations of this disease. Based on a study by Issak et al. on 112 patients with RP, one out of four had laryngotracheal symptoms [30]. The symptoms include change in voice quality, respiratory discomfort, stridor, dyspnea, cough, chocking, anterior neck tenderness mainly over the thyroid cartilage and cricoid cartilages, aspiration and difficulty in swallowing. The severity of these symptoms may vary with the extent of the disease and site of laryngeal involvement. Laryngotracheal obstruction may progress to respiratory obstruction and death. The obstruction can be 
secondary either to cicatricial narrowing and inflammation, or to collapse of the airway secondary to cartilage destruction [31]. Similarly, dysphonia may evolve into complete aphonia with erosion of the cricoarytenoid joint $[9,32,33]$. When the vocal cords can not assume the adductor position, phonation is impaired and patients can not build enough subglottic pressure to set the vocal cords into vibration. For the same reason, cough is weakened and patients fail to clear their own secretions. Excessive inflammation and scarring may also impair mucociliary clearance and result in pulmonary infection. Erosion and collapse of the cartilaginous structures of the upper airway can result in complete obstruction and at times even dislocation in the laryngotracheal complex and costochondral cartilages. Resultant subglotic stenosis seems to be more common in younger women. Even non cartilaginous structures may be affected secondary to the accompanying vasculitic process [34,35]. Patient should be advised to avoid any laryngeal or tracheal manipulation, as this might exacerbate pre-existing pathology and accelerate the disease progress. See Table 1.

Another rare laryngeal manifestation of this disease is bamboo nodes. These are yellowish transverse submucosal lesions that develop in the membranous portion of the vocal cords in patients with autoimmune diseases [36]. Affected patients with these lesions may complain of hoarseness and a variety of phonatory symptoms.

\section{Treatment}

Early awareness of the laryngeal involvement in patients with relapsing polychondritis is crucial for proper care and good outcome. Patients with respiratory tract involvement are invariably treated with high dose steroid that is maintained for a long term. A recent report by Minami et al. describes the outcome of high dose steroid in 5 patients with RP. In his report all five patients improved on steroids except for three who had recurrence once the dosage has been reduced. These patients were treated with either immunosuppressive therapy or with steroid plus therapy [37]. Wang et al. also highlights in his report on a 37-year-old female the importance of the multimodality treatment of patients with relapsing polychondritis with otolaryngologic manifestations [38]. Methotrexate is also administered as an adjunct therapy, more so for patients who can't tolerate the side effects of high dose steroid therapy $[39,40]$. Other adjunctive therapeutic medications used in conjunction with steroids are Azathioprine, cyclophosphamide, Cyclosporin A, antiCD4 monoclonal antibodies and dapsone [41-47].

Another option for the treatment of laryngotracheal involvement in patients with RP is surgery. The anaesthetic management of these patients is very important given their critical airway and the potential drastic effect of laryngotracheal manipulation. Tanaka TT et al. describes the importance of manipulating the airway the least using positive end-expiratory pressure and or small endotracheal tubes in patients with inflammation and destructed laryngotrachea in relapsing polychondritis [48]. The surgical intervention in these patients varies from tracheostomy, to serial dilatation, to laryngotracheal reconstruction with or without stenting. Karaman et al. described laryngotracheal reconstruction in three female patients with RP affecting the laryngotracheal complex [49]. A recent report by Zhang et al. on thirteen cases with RP highlights the importance of airway surgical intervention at later stages of the diseases. The use of metallic stents in addition to tracheostomy and positive airway pressure is often needed to treat the airway in affected patients [50]. Heman Ackah et al. have reported the use of silicone mold material substance as an alternative to prefabricated stents in laryngotracheal reconstruction. The added value of this material lies in its conformity with the endolaryngeal lumen and its ease of removal [51].

The bamboo nodes are treated either with phonosurgery using microflap technique sparing the overlying mucosa or by the pulsed-potassium Titanyl-phosphate (KTP) laser which eventually causes resolution of the lesion and improvement in dysphonia [52]. Childs et al. in their report on three patients with laryngotracheal involvement in RP, one of whom presenting with bamboo nodes, introduces the aforementioned laser therapy as a novel

Table 1. Laryngeal manifestations of relapsing polychondritis.

\begin{tabular}{|c|c|c|c|}
\hline Epidemiology & L. Symptoms & L. Findings & Radiologic Findings \\
\hline $3.5 \% / 1,000,000$ & Dysphonia/Aphonia & Inflammation & Calcific tracheal deposits \\
\hline Age 5 - 84 years & Respiratory Distress & Scar formation & Cartilage erosion \\
\hline \multirow[t]{5}{*}{$\mathrm{M} / \mathrm{F} 1: 1$ - 1:3 } & Stridor & Cartilage Collapse & Mucosal thickening \\
\hline & Cough & Cartilage erosion & Scarring and Fibrosis \\
\hline & Aspiration & Narrowed airway & Airway collapse \\
\hline & Neck pain & Impaired/Fixed cord & \\
\hline & Dysphagia & Bamboo nodes & \\
\hline
\end{tabular}


treatment option.

\section{Conclusion}

Relapsing Polychondritis is a systemic disease with dreadful laryngeal manifestations. Affected patients with symptoms of the upper aero-digestive system require an immediate clinical and radiologic evaluation. Thorough assessment of the laryngopharyngeal complex with early intervention is mandatory in order to avoid airway complications and death.

\section{REFERENCES}

[1] R. Jaksch-Wartenhorst, “Polychondropathia,” Wien Archives of Internal Medicine, Vol. 6, 1923, pp. 93-100.

[2] A. F. Uber, "Eiven Fall Von Systematisierter Chondromalacia," Virchows Archiv für pathologische Anatomie und Physiologie und für klinische Medizin, Vol. 297, No. 3, 1936, pp. 445-479. doi:10.1007/BF01892722

[3] T. R. Harwood, "Diffuse Perichondritis, Chondritis, and Iritis," Archives of Pathology, Vol. 65, No. 1, 1958, pp. 81-87.

[4] M. C. Pearson, M. H. Kline and D. V. Newcomer, "Relapsing Polychondritis, Chondritis, and Iritis,” New England Journal of Medicine, Vol. 263, No. 2, 1960, pp. 5158. doi:10.1056/NEJM196007142630201

[5] W. B. Bean, C. C. Drevets and J. S. Chapman, "Chronic Atrophic Polychondtritis,” Medicine, Vol. 37, No. 4, 1958, pp. 353-363. doi:10.1097/00005792-195812000-00004

[6] W. B. Reed, "Relapsing Polychondritis (Diffuse Chondrolysis)," Archives of Dermatology, Vol. 106, No. 3, 1972, p. 412. doi:10.1001/archderm.106.3.412b

[7] H. Spencer, "Pathology of the Lung," 3rd Edition, WB Saunders, Philadelphia, 1977, pp. 759-761.

[8] H. S. Luthra, "Relapsing Polychondritis,” In: J. H. Klippel and P. A. Dieppe, Eds., Rheumatology, Vol. 27, Mosby, St. Louis, 1998, pp. 1-4.

[9] D. E. Trentam and C. H. Le, "Relapsing Polychondritis," Annals of Internal Medicine, Vol. 129, No. 2, 1998, pp. 114-122. doi:10.7326/0003-4819-129-2-199807150-00011

[10] C. Frances, R. E. Rasi, J. L. Laporte, M. Rybojad, T. Papo and J. C. Piette, "Dermatologic Manifestation of Relapsing Polychondritis: A Study of 200 Cases at a Single Center,” Medicine, Vol. 8, No. 3, 2001, pp. 173-179. doi:10.1097/00005792-200105000-00003

[11] C. R. Arkin and A. T. Masi, "Relapsing Polychondritis: Review of Current Status and Case Report," Seminars in Arthritis and Rheumatism, Vol. 5, No. 1, 1975, pp. 41-62. doi:10.1016/0049-0172(75)90022-0

[12] F. W. Arudell and J. R. Haserick, "Familial Chronic Atrophic Polychondritis,” Archives of Dermatology, Vol. 82, No. 3, 1960, pp. 439-441.

[13] T. Papo, B. Wechsler, O. Bletry, A. M. Piette, P. Godeau and J. C. Piette, "Pregnancy in Relapsing Polychondritis," Arithritis and Rheumatism, Vol. 40, No. 7, 1997, pp.
1245-1249. doi:10.1002/art.8

[14] J. M. Foidart, S. Abe, G. R. Martin, T. M. Zizic, E. V. Barnett, T. J. Lawley, et al., "Antibodies to Type II Collagen in Relapsing Polychondritis,” New England Journal of Medicine, Vol. 299, No. 22, 1978, pp. 1203-1207. doi:10.1056/NEJM197811302992202

[15] L. Giroux, F. Paquin, M. J. Guerard-Desjardins and A. Lefaivre, "Relapsing Polychondritis: An Autoimmune Disease," Seminars in Arthritis and Rheumatism, Vol. 13, No. 2, 1983, pp. 182-187. doi:10.1016/0049-0172(83)90005-7

[16] J. S. Courtenay, M. J. Dallman, A. D. Dayan, A. Martin and B. Mosedale, "Immunization against Heterologous Type II Collagen Induces Arthritis in Mice,” Nature, Vol. 283, No. 5748, 1980, pp. 666-668. doi:10.1038/283666a0

[17] L. P. McAdam, M. A. O’Hanlan, R. Bluestone and C. M. Pearson, "Relapsing Polychondritis: Prospective Study of 23 Patients and a Review of the Literature," Medicine, Vol. 55, No. 3, 1976, pp. 193-215. doi:10.1097/00005792-197605000-00001

[18] J. M. Damiani and H. L. Levine, "Relapsing Polychondritis Report of Ten Cases,” Laryngoscope, Vol. 89, 1979, pp. 929-944.

[19] C. J. Michet, C. H. McKenna, H. S. Luthra and W. M. O’Fallon, "Relapsing Polychondritis: Survival and Predictive Role of Early Disease Manifestations," Annals of Internal Medicine, Vol. 104, No. 1, 1986, pp. 74-78. doi:10.7326/0003-4819-104-1-74

[20] J. M. Damiani and H. L. Levine, "Relapsing Polychondritis Report of Ten Cases,” Laryngoscope, Vol. 89, No. 6, 1979, pp. 929-943.

[21] R. O. Williams, D. G. Williams and R. N. Maini, "AntiType II Collagen ELISA Increased Disease Specificity Following Removal of Anionic Contaminants from SaltFractionated Type II Collagen,” Journal of Immunological Methods, Vol. 147, No. 1, 1992, pp. 93-100. doi:10.1016/S0022-1759(12)80033-0

[22] L. P. McAdam, M. A. O’Hanlan, R. Bluestone and C. M. Pearson, "Relapsing Polychondritis: Prospective Study of 23 Patients and a Review of the Literature,” Medicine, Vol. 55, No. 3, 1976, pp. 193-215. doi:10.1097/00005792-197605000-00001

[23] J. L. Port, A. Khan and R. R. Barbu, "Computed Tomography of Relapsing Polychondritis,” Computerized Medical Imaging and Graphics, Vol. 17, No. 2, 1993, pp. 119-123. doi:10.1016/0895-6111(93)90053-P

[24] M. Oddone, P. Toma, A. Taccone, G. Hanau, A. Delogu and G. Gemme, "Relapsing Polychondritis in Childhood: a Rare Observation Studied by CT and MRI,” Pediatric Radiology, Vol. 22, No. 7, 1992, pp. 537-538. doi:10.1007/BF02013006

[25] H. R. Neeson, K. B. Remley, A. E. Stillman and F. L. Rimell, "Dynamic MR Imaging of the Larynx and Trachea," The American Society of Neuroradiology 34th Annual Meeting, Seattle, 23-27 June 1996.

[26] J. A. Fornadley, D. J. Seibert, B. E. Ostrov and W. S. Warren, "The Role of MRI when Relapsing Polychondritis is Suspected but not Proven," International Journal of 
Pediatric Otorhinolaryngology, Vol. 31, No. 1, 1995, pp. 101-107. doi:10.1016/0165-5876(94)01068-9

[27] J. Eng and S. Sabanathan, "Airway Complications in Relapsing Polychondritis," The Annals of Thoracic Surgery, Vol. 51, No. 4, 1991, pp. 686-692. doi:10.1016/0003-4975(91)90348-T

[28] K. S. Lee, A. Ernst, D. E. Trentham, et al., "Relapsing Polychondritis: Prevalence of Expiratory CT Airway Abnormalities,” Radiology, Vol. 240, No. 2, 2006, pp. 565573. doi:10.1148/radiol.2401050562

[29] H. E. Eckel, C. Wittekindt, U. Schroeder, J. P. Klussmann and C. Sittel, "Management of Bilateral Arytenoids Cartilage Fixation versus Recurrent Laryngeal Nerve Paralysis,” The Annals of Otology, Rhinology, and Laryngology, Vol. 112, No. 2, 2003, pp. 103-108.

[30] W. S. Copeman, "Rheumatoid Arthritis of the Cricoarytenoid Joints,” British Medical Journal, Vol. 1, No. 5032, 1957, pp. 1398-1399. doi:10.1136/bmj.1.5032.1398

[31] H. Bienenstock, G. E. Ehrlich and R. H. Freyberg, "Rheumatoid Arthritis of the Cricoarytenoid Joints: A Clinicopathologic Study,” Arthritis \& Rheumatism, Vol. 6, No. 1, 1963, pp. 48-63. doi:10.1002/art.1780060106

[32] D. L. Dolan, G. B. Lemmon and S. L. Teitelbaum, "Relapsing Polychondritis Analytical Review and Studies on Pathogenesis," The American Journal of Medicine, Vol. 41, No. 2, 1966, pp. 285-299. doi:10.1016/0002-9343(66)90023-4

[33] G. J. Gibson and P. Davis, "Respiratory Complications of Relapsing Polychondritis,” Thorax, Vol. 29, No. 6, 1974, pp. 726-731. doi:10.1136/thx.29.6.726

[34] B. D. Sarodia, A. Dasgupta and A. C. Mehta, "Management of Airway Manifestations of Relapsing Polychondritis: Case Reports and Review of Literature," Chest Journal, Vol. 116, No. 6, 1999, pp. 1669-1675. doi:10.1378/chest.116.6.1669

[35] P. D. Kent, C. J. Michet and H. S. Luthra, "Relapsing Polychondritis,” Current Opinion in Rheumatology, Vol. 16, No. 1, 2003, pp. 56-61. doi:10.1097/00002281-200401000-00011

[36] E. Hilgert, B. Toleti, K. Kruger and I. Nejedlo, "Hoarseness Due to Bamboo Nodes in Patients with Autoimmune Diseases: A Review of Literature," Journal of Voice, Vol. 22, No. 3, 2008, pp. 343-350. doi:10.1016/j.jvoice.2006.10.009

[37] R. Minami, T. Miyamura, M. Nakamura, et al., "A Clinical Study of Five Cases Demonstrating Relapsing Polychondritis,” Nihon Rinsho Meneki Gakkai Kaishi, Vol. 32, No. 4, 2009, pp. 269-273. doi:10.2177/jsci.32.269

[38] T. Wang, Q. Lu, Y. Qin and N. He, "The Diagnosis and Treatment of Relapsing Polychondritis (A Case Report)," Lin Chung Er Bi Yan Hou Tou Jing Wai Ke Za Zhi, Vol. 22, No. 13, 2008, pp. 590-592.

[39] J. Grosflam and M. E. Weinblatt, "Methotrexate: Mechanism of Action, Pharmacokinetics, Clinical Indications, and Toxicity," Current Opinion in Rheumatology, Vol. 3, No. 3, 1991, pp. 363-368. doi:10.1097/00002281-199106000-00006

[40] J. Park, K. M. Gowin, H. R. Schumacher Jr., "Steroid
Sparing Effect of Methotrexate in Relapsing Polychondritis,” The Journal of Rheumatology, Vol. 23, No. 5, 1996, pp. 937-938.

[41] A. Chang-Miller, M. Okamura, V. E. Torres, et al., "Renal Involvement in Relapsing Polychondritis," Medicine, Vol. 66, No. 3, 1987, pp. 202-217. doi:10.1097/00005792-198705000-00004

[42] K. L. G. Svenson, R. Holmdahl, L. Klareskog, et al., “Сyclosporin a Treatment in a Case of Relapsing Polychondritis," Scandinavian Journal of Rheumatology, Vol. 13, No. 4, 1984, pp. 329-333. doi:10.3109/03009748409111304

[43] K. Svenson, S. O. Bohman and R. Hallgren, "Renal Interstitial Fibrosis and Vascular Changes. Occurrence in $\mathrm{Pa}$ tients with Auroimmune Diseases Treated with Cyclosporine," Formerly Archives of Internal Medicine, Vol. 146, No. 10, 1986, pp. 2007-2010. doi:10.1001/archinte.1986.00360220169028

[44] A. Anstey, S. Mayou, K. Morgan, R. B. Clague and D. D. Munro, "Relapsing Polychondritis: Autoimmunity to Type II Collagen and Treatment with Cyclosporin A," British Journal of Dematology, Vol. 125, No. 6, 1993, pp. 588-591. doi:10.1111/j.1365-2133.1991.tb14801.x

[45] E. H. S. Choy, I. C. Chikanza, G. H. Kingsley and G. S. Panayi, "Chimaeric Anti-CD4 Monoclonal Antibody for Relapsing Polychondritis,” The Lancet, Vol. 338, No. 8764, 1991, pp. 338-450.

[46] A. D. Ormerod and L. J. Clark, "Relapsing Polychondritis-Treatment with Cyclosporin A," British Journal of Dematology, Vol. 127, No. 3, 1992, p. 300. doi:10.1111/j.1365-2133.1992.tb00135.X

[47] P. A. Van der Lubbe, A. M. Miltenburg and F. C. Breedveld, “Anti-CD4 Monoclonal Antibody for Relapsing Polychondritis,” The Lancet, Vol. 337, No. 8753, 1991, p. 1349. doi:10.1016/0140-6736(91)93023-3

[48] T. T. Tanaka, H. F. Furutani and T. H. Harioka, “Anaesthetic Management of a Patient with Relapsing Polychondritis Undergoing Laparoscopic Surgery,” Anaesth Intensive Care Journal, Vol. 34, No. 3, 2006, pp. 372374.

[49] E. Karaman, C. Duman, H. Cansz, M. Ylmaz and M. Ibrahimov, "Laryngotracheal Reconstruction at Relapsing Polychondritis,” Journal of Craniofacial Surgery, Vol. 21, No. 1, 2010, pp. 211-212. doi:10.1097/SCS.0b013e3181c50f7d

[50] J. Q. Zhang, Q. Li, C. Bai, Y. Huang, Y. C. Dong, X. P. Yao and Q. Wang, "Clinical Features and Treatment of Relapsing Polychondritis with Involvement of the Respiratory Tract-Report of Thirteen Cases," Zhonghua Jie He He Hu Xi Za Zhi, Vol. 30, No. 3, 2007, pp. 173-177.

[51] Y. D. Heman-Ackah and R. T. Sataloff, "Use of Silicone Hearing Aid Mold Material in Laryngotracheal Reconstruction," The Annals of Otology, Rhinology and Laryngology, Vol. 114, No. 10, 2005, pp. 739-742.

[52] L. F. Childs, S. Rickert, O. C. Wengerman, R. Lebovics and A. Blitzer, "Laryngeal Manifestations of Relapsing Polychondritis and a Novel Treatment Option,” Journal of Voice, Vol. 26, No. 5, 2012, pp. 587-589. doi:10.1016/j.jvoice.2011.07.012 